\title{
PONTOS DE VISTA DE FORMADORES SOBRE O ENSINO DE TEXTOS ORAIS: POR QUÊ? O QUÊ? COMO?
}

\author{
Ewerton Ávila dos Anjos Luna*
}

\begin{abstract}
Resumo: Considerando a relevância da formação inicial do professor de português para o processo de construção de saberes docentes sobre o ensino da oralidade, este estudo objetivou investigar o que pensam professores universitários sobre o porquê de contemplar textos orais na escola, quais gêneros textuais devem ser selecionados e como viabilizar estratégias didáticas nas práticas de ensino. Para isso foram entrevistados cinco formadores que atuam em um curso de Licenciatura em Letra-Português. Os dados apontaram que, mesmo com algumas inquietações, a fala dos docentes está em conformidade com o que preconizam documentos oficiais e com o que tem sido evidenciado por estudos recentes.
\end{abstract}

Palavras-chave: Licenciatura em Letras-Português. Didática da oralidade. Opinião de professores universitários.

\begin{abstract}
Considering the relevance of initial formation of Portuguese teachers in the process of knowledge construction on the teaching of orality, this study aimed at investigating what university professors think about the reasons to contemplate oral texts in school, which textual genres should be selected and how to implement feasible didactical strategies in teaching practices. In order to reach this goal, five professors in a Letters course for future Portuguese teachers were interviewed. Data pointed out that, even with some restlessness, educators' speeches are in conformity to what official documents guide and to what has been revealed by recent studies.
\end{abstract}

Keywords: Portuguese teaching degree. Didactics of orality. Professors' opinion.

\section{Introdução}

As várias contribuições dadas por diferentes correntes linguísticas trouxeram repercussões importantes para o ensino da oralidade no Brasil. Isso ficou refletido nos documentos oficiais publicados pelo Ministério e Secretarias de Educação do país, indicando um importante avanço para as políticas de ensino de língua materna, com consequências, de algum modo, para o processo de ensino-aprendizagem.

Os Parâmetros Curriculares Nacionais (BRASIL, 1998), por exemplo, dedicam seções destinadas à prática de escuta e à prática de produção de textos orais, onde são sugeridos gêneros textuais - pertencentes aos domínios literário, midiático e científico - a serem privilegiados com a seguinte justificativa:

Nas inúmeras situações sociais do exercício da cidadania que se colocam fora dos muros da escola [...] os alunos serão avaliados (em outros termos, aceitos ou discriminados) à medida que forem capazes de responder a diferentes exigências de fala e de adequação às características próprias de diferentes gêneros do oral (BRASIL, 1998, p. 25).

Se por um dado, a escola deve tomar para si, de acordo com os PCN, a tarefa de ensinar procedimentos apropriados para a fala e a escuta em contextos públicos; por outro, estudos apontam que, mesmo após mais de uma década da publicação do referido documento, professores ainda possuem dificuldades para a realização de um trabalho sistemático com os textos orais na aula de português (RODRIGUES; LUNA, 2016).

\footnotetext{
* Doutor em Linguística. Professor da Universidade Federal Rural de Pernambuco. Endereço eletrônico: ewertonavila2@gmail.com
} 
Partindo da hipótese de que a formação inicial pode trazer lacunas quanto à didática da oralidade, buscou-se investigar, neste estudo, o que pensam professores universitários sobre aspectos como o porquê do ensino da oralidade na escola, quais gêneros textuais devem ser contemplados e como fazer um trabalho sistemático com este eixo de ensino.

Os dados, portanto, são apresentados e analisados no tópico 4; antes, porém, é feita uma breve reflexão teórica a partir de estudos empíricos recentemente publicados sobre oralidade e práticas pedagógicas (tópico 2); além de serem pontuados percursos metodológicos (tópico 3).

\section{Reflexões sobre estudos de oralidade e ensino}

Apesar de o ensino-aprendizagem da oralidade ser temática presente em documentos oficiais como, por exemplo, os PCN (BRASIL, 1998) e os Parâmetros para Educação Básica do Estado de Pernambuco, doravante PEB-PE (PE, 2012), várias pesquisas têm demonstrado que o avanço teórico - referente a concepções importantes - que fundamentam estes documentos ainda não implica avanço das práticas pedagógicas. O estudo de Ávila, Nascimento e Gois, publicado em 2012, com dados coletados em 2010 - ou seja, 12 anos após a publicação dos PCN - apontou esse fato ao evidenciar respostas insatisfatórias dadas por parte significativa de professores quando questionados sobre o porquê de se trabalhar com textos orais na aula de língua portuguesa, quais gêneros textuais orais estão presentes na escola e como tratar gêneros orais enquanto objeto de ensino. Segundo os autores,

A efetiva mobilização desses saberes [trabalho com gêneros orais] na prática docente é algo que requer ações contínuas que lhes deem acesso a mais informações pertinentes sobre este tema, assim como oportunidade de partilharem experiências com outros professores que, em diferentes lugares do país, exercitem a capacidade de ressignificar seu fazer pedagógico. (ÁVILA; NASCIMENTO; GOIS, 2012, p. 54).

$\mathrm{O}$ acesso aos PCN, por exemplo, não é suficiente para o redirecionamento de práticas. Isso porque a sua leitura não garante a compreensão de conceitos que podem não ter sido introduzidos ou compreendidos na formação inicial docente, ou não garantem um processo de transposição didática adequado, seguindo os fundamentos do que está posto no documento.

Em 2014, quatro anos após a coleta dos dados da primeira pesquisa, Rodrigues e Luna (2016) aplicaram o questionário com as mesmas perguntas, mas para professores diferentes. A primeira pesquisa foi realizada com docentes de diferentes municípios do estado do Piauí e a segunda com professores da rede municipal de Recife. As respostas caminharam na mesma direção da pesquisa anterior.

Outro revelador estudo sobre os documentos oficiais e o ensino da oralidade é o de Magalhães (2007); nele, a autora confronta as concepções presentes nos PCN com as do Guia do Programa Nacional do Livro Didático de 2005 (PNLD-2005), além de analisar livros didáticos de português aprovados nesse PNLD. Segundo Magalhães, trata-se de um estudo que lida com objetivos teóricos (PCN), postulados teórico-práticos (GUIA PNLD/2005) e o principal suporte didático das aulas de português (Livros didáticos). Os resultados da pesquisa indicam que, apesar de serem produzidos pela mesma instituição (Ministério da Educação), a concepção de oralidade é divergente, permitindo a aprovação de livros que contemplem a 
oralidade, mas não de forma sistemática. É devido a isso, segundo a autora, a existência da grande quantidade de atividades nos livros de conversa com o colega e de leitura em voz alta ${ }^{1}$.

Magalhães (2007, p. 138) conclui que o fato de o professor ser bastante dependente dos materiais, em função de várias razões, faz com que o guia do PNLD componha "um parâmetro à parte mais importante até que os próprios PCN, o que constitui um paradoxo", já que estes formulariam intenções e aquele contribuiria, de fato, para a ação. Corroboramos conclusões da autora no que se refere ao fato de que o construto teórico que fundamenta os PCN não está sendo muitas vezes considerado em sua essência por muitos atores (professores, autores de livros didáticos, etc.) e/ou instâncias (programas nacionais) em função de uma visão mais "flexível" das propostas práticas para o ensino do eixo da oralidade.

Já o estudo etnográfico de Botler (2013) segue numa direção contrária ao de Rodrigues e Luna (2016). A partir da realização de entrevistas, análises de planos e observações de aulas dos dois sujeitos da pesquisa (professor dos anos finais do Ensino Fundamental do Colégio de Aplicação da UFPE e da Rede Estadual de Pernambuco), a pesquisadora afirma que os dados mostraram a realização de um trabalho sistemático com o oral, coerente com a concepção de linguagem e oralidade numa perspectiva sociointeracionista adotada por ambas.

Se o estudo de Rodrigues e Luna (2016) mostra uma grande dificuldade dos professores em trabalhar com a oralidade, o estudo de Botler (2013) evidencia outros resultados. Já o estudo de Costa-Maciel (2013) traz conclusões que apontam para uma posição intermediária quando comparamos os outros dois estudos citados. Costa-Maciel (2013) realiza seu trabalho com três professoras dos anos iniciais do Ensino Fundamental. Em suas conclusões, afirma:

Nossa conversa com as docentes revelou muitas demandas no campo de formação de professores, mas também nos fez ver ensaios de um trabalho com o oral que parece ser iniciado, ainda que de modo mais informal, no dia a dia da escola. A configuração de demandas, incertezas e algumas certezas ganha elevadas proporções quando se trata de ensinar o objeto didático oralidade, uma vez que navegar pelo referido eixo, na posição que toma o oral como veículo de comunicação e como objeto de ensino-aprendizagem é um desafio constante para as ações das políticas de formação docentes, no âmbito inicial e continuado. (COSTA-MACIEL, 2013, p. 126).

Como se percebe, apesar das dificuldades encontradas, um trabalho com o oral é realizado. No que se refere à formação docente, os sujeitos da pesquisa atribuem seus conhecimentos sobre o ensino da oralidade a uma série de saberes de ordens distintas. Apontam que suas formações iniciais - o magistério - foram insuficientes principalmente porque ocorreu há muito tempo atrás. Então, seus saberes foram construídos a partir das

\footnotetext{
${ }^{1}$ O Guia do PNLD-2015 ratifica o que é posto por Magalhães quando aponta que das 10 coleções aprovadas, “o trabalho com a oralidade está significativamente presente em ao menos quatro dos manuais e em um dos compêndios deste Guia" (BRASIL, 2014, p. 23). É afirmado, ainda: "Em contrapartida, a oralidade aparece, nas demais coleções, como atividade-meio, e não como atividade-fim: em algumas obras, episódica e pontualmente; em outras, de forma regular e significativa. Em consequência, a linguagem oral é tratada como uma competência já adquirida, mobilizada principalmente em propostas de leitura e/ou produção de textos. Conversas com os colegas, trocas de opiniões e discussões em sala de aula sobre um tema determinado são as sugestões mais recorrentes, deixando-se de lado os usos públicos e formais da oralidade. Na grande maioria dos casos, não há orientações específicas; em outras coleções, as instruções são genéricas, restritas ao indispensável para viabilizar o encaminhamento do trabalho com leitura, escrita ou conhecimentos linguísticos" (BRASIL, 2014, p. 23).
} 
formações continuadas, das práticas de sala de aula e da interação com os pares (COSTAMACIEL, 2013).

Outra pesquisa relevante cujos resultados apontam dificuldades na formação inicial do professor em função de déficit dos formadores é a de Araújo, Rafael e Amorim (2013). Os autores investigam ementas e programas de disciplinas, através de entrevistas, a fim de identificar como a oralidade é contemplada na licenciatura: como objeto de estudo, ou seja, a descrição da língua, os estudos linguísticos; e/ou como objeto de ensino, em que se reflete sobre como os futuros professores irão ensinar a oralidade.

Esse estudo recente aponta que os componentes curriculares contemplam sobretudo questões teóricas: "Há pouca ou nenhuma indicação de transposição. Logo, não se espera que os licenciandos saibam fazer como profissionais”. (ARAÚJO; RAFAEL; AMORIM, 2013, p. 71). Quando o foco recai sobre o depoimento dos professores, a preocupação com a transposição faz-se presente, embora ainda pouco. Em termos conclusivos, a pesquisa aponta que, por um lado, há fortes heranças do estruturalismo linguístico e, por outro, quando se considera os paradigmas da 'virada linguística' - em que a oralidade é concebida como conjunto de práticas linguísticas que viabilizam diferentes funções sociais de interação - os postulados sobre oralidade são superficiais:

As relações entre fala e escrita são limitadas às diferenças entre formalidade e informalidade; a variação linguística é reduzida a 'erro' linguístico, tendo a escrita formal como modelo hegemônico; e o estudo dos gêneros orais é limitado à descrição do texto. (ARAÚJO; RAFAEL; AMORIM, 2013, p. 74).

As pesquisas citadas, voltadas para a prática docente e a formação do professor, indicam que a discussão sobre o ensino da oralidade no Brasil está crescendo cada vez mais. A realização dos estudos, sua divulgação, as contribuições da linguística, as reflexões lançadas pela Linguística Aplicada ao ensino, a publicação de documentos oficiais, a avaliação de materiais didáticos, são, em conjunto, importantes para o fortalecimento do debate sobre o ensino da oralidade.

\section{Metodologia}

$\mathrm{Na}$ pesquisa que desenvolvemos, foram entrevistados cinco professores universitários que atuam em uma Instituição Federal de Ensino Superior no estado de Pernambuco e que são formadores responsáveis por componentes curriculares de metodologias de ensino e estágios de um curso de Licenciatura em Letras-Português ${ }^{2}$.

$\mathrm{Na}$ entrevista, foi solicitado aos formadores que fizessem comentários sobre o trabalho com oralidade na escola a partir de fragmentos do que foi apontado por professores de português, disponibilizados em ficha impressa, retirados do estudo de Ávila, Nascimento e Gois (2012).

A ficha era composta por três partes. Na primeira havia opiniões sobre o porquê de trabalhar com textos orais na escola; na segunda, sobre quais gêneros orais estão presentes nas escolas; e, na terceira, sobre como tratar gêneros orais como objeto de ensino. O Quadro seguinte contém os fragmentos lidos pelos formadores no momento da entrevista:

\footnotetext{
${ }^{2}$ Embora os colaboradores desta pesquisa não sejam identificados, informamos que os mesmos concordaram em contribuir com o estudo e que assinaram o Termo de consentimento livre e esclarecido.
} 
Quadro 1: Ficha utilizada em entrevista

\begin{tabular}{|c|c|c|}
\hline Por quê? & Quais gêneros? & Como? \\
\hline $\begin{array}{l}\text { 1. Eu sempre trabalhei a } \\
\text { oralidade em sala de aula } \\
\text { porque quando eu estudei } \\
\text { não trabalharam a minha } \\
\text { oralidade e eu sou tímida. } \\
\text { Portanto, eu não quero que } \\
\text { meus alunos sofram com a } \\
\text { timidez; } \\
\text { 2. Por acreditar que eles } \\
\text { [alunos] precisam do espaço } \\
\text { para desenvolver atividades } \\
\text { de integração com a turma; } \\
\text { 3. Não é uma prática muita } \\
\text { aceita por outros professores, } \\
\text { pois gera bagunça. }\end{array}$ & $\begin{array}{l}\text { - Leitura de textos literários } \\
\text { como: poesia, crônica, } \\
\text { romance, letra de músicas, } \\
\text { entre outros. } \\
\text { - Todos os gêneros que } \\
\text { trabalhei e trabalho em sala } \\
\text { de aula eu considero gênero } \\
\text { da oralidade (contos, } \\
\text { crônicas, propagandas, } \\
\text { charges, piadas e etc.). } \\
\text { Cantigas de roda, vídeos de } \\
\text { contos infantis e desenhos } \\
\text { animados, discursos políticos } \\
\text { gravados, palestras e músicas } \\
\text { populares e da cultura local... } \\
\text { Depoimentos, seminários, } \\
\text { entrevistas, programas de } \\
\text { rádio, narração de um jogo. }\end{array}$ & $\begin{array}{l}\text { - Após a leitura dos textos é } \\
\text { feito um debate entre os } \\
\text { alunos, onde os alunos } \\
\text { expressam seus pontos de } \\
\text { vista, as ideias, dando suas } \\
\text { opiniões (P243). } \\
\text { - Com o debate, nós discutimos } \\
\text { em grupo sobre diferentes } \\
\text { temas da atualidade, } \\
\text { principalmente aqueles que } \\
\text { serão abordados nas redações } \\
\text { futuras (P5). } \\
\text { - Perguntei se alguém conhecia } \\
\text { [o gênero entrevista]. Eles } \\
\text { responderam que já tinham } \\
\text { visto na TV. Perguntei sobre } \\
\text { os elementos essenciais. } \\
\text { Lemos uma entrevista com } \\
\text { Gabriel Pensador. Questionei } \\
\text { sobre as marcas da oralidade } \\
\text { [...]. Em seguida, perguntei } \\
\text { quem eles gostariam de } \\
\text { entrevistar [...]. Elaboraram as } \\
\text { perguntas e saíram em campo } \\
\text { muito animados (P32). }\end{array}$ \\
\hline
\end{tabular}

Fonte: Adaptado de Ávila, Nascimento e Gois (2012).

As entrevistas deste estudo, de natureza qualitativa, foram semi-estruturadas, permitindo que a sequência dos aspectos discutidos seguisse uma ordem flexível, sendo determinada muitas vezes pelos ganchos possíveis advindos das atenções que os entrevistados deram aos tópicos em andamento. Os registros foram feitos através de gravação (áudio) das entrevistas.

\section{Análise dos dados}

Em relação ao porquê do trabalho com a oralidade na aula de Português, excetuandose $\mathrm{F}^{4}$ que acredita ser válido trabalhar em prol da timidez, da integração e do respeito, os demais formadores discordaram fortemente das opiniões de docentes que focam no oral apenas com o objetivo de diminuir a timidez do aluno e integrar a turma ou que associam à geração de bagunça. F10, por exemplo, afirma: "timidez não seria a questão central do professor de português. Não é uma questão linguística, é mais social, psíquica e tal” (F10).

Ainda sobre o papel do professor de português, F8, ao comentar sobre as atividades de debate relatadas na terceira parte da ficha, faz uma crítica:

Eu acho que trabalha a oralidade, mas aqui o foco não é o debate em si, como objeto de ensino, às vezes é o tema do texto, são os valores, são as

\footnotetext{
3 "P" no referido estudo (ÁVILA; NASCIMENTO; GOIS, 2012) significa "Professor".

${ }^{4}$ Os cincos formadores serão chamados de F6, F7, F8, F9 e F10.
} 
crenças, é essa coisa que eu falei que o professor de português tem muito, que é o trabalho com atitudes, com valores, com temas, e o debate tá ali, não pra ensinar o debate, mas pra discutir um tema polêmico, um texto (F8).

No caso do excerto, F8 aponta a falta de foco no oral como objeto de ensino, uma vez que o gênero debate ou outras estratégias da fala não são trabalhados, mas aponta o trabalho com o texto (provavelmente escrito e lido pelos alunos para desencadear o debate), ou seja, elemento de natureza linguística, e acrescenta ainda o acréscimo de 'trabalho com atitudes' e 'valores' o que seria um aspecto transversal ao ensino de português e pertencente à escola independente da área de conhecimento escolar.

Acreditamos que o professor de português deve ter como foco o desenvolvimento de competências e habilidades linguísticas, por mais que estas estejam associadas a outros aspectos. De acordo com os PCN (BRASIL, 1998), é papel do professor de português realizar atividades que permitam ao aluno:

- utilizar a linguagem na escuta e produção de textos orais e na leitura e produção de textos escritos de modo a atender a múltiplas demandas sociais, responder a diferentes propósitos comunicativos e expressivos, e considerar as diferentes condições de produção do discurso;

- utilizar a linguagem para estruturar a experiência e explicar a realidade, operando sobre as representações construídas em várias áreas do conhecimento $[\ldots]$;

- analisar criticamente os diferentes discursos, inclusive o próprio, desenvolvendo a capacidade de avaliação dos textos [...];

- conhecer e valorizar as diferentes variedades do Português, procurando combater o preconceito linguístico;

- reconhecer e valorizar a linguagem de seu grupo social como instrumento adequado e eficiente na comunicação cotidiana, na elaboração artística e mesmo nas interações com pessoas de outros grupos sociais que se expressem por meio de outras variedades;

- usar os conhecimentos adquiridos por meio da prática de análise linguística para expandir sua capacidade de monitoração das possibilidades de uso da linguagem, ampliando a capacidade de análise crítica. (BRASIL, 1998, p. 32-33).

Como se pode observar na citação, o foco central de todos os tópicos é a linguagem. Centrando-se na oralidade, F10 também indica que concorda com essa ideia ao se posicionar sobre o ensino do oral para integração da turma: "tem uma oralidade mais espontânea da própria sala de aula, mas o oral a se aprender é o formal”. Ou seja, a integração através da oralidade é possível, mas o papel do professor de português é ensinar o que o aluno não sabe. Em outras palavras, a integração entre crianças e adolescentes irá acontecer, sobretudo, através de gêneros textuais informais como a conversação. Por outro lado, o professor precisa trabalhar com estruturas mais complexas que exijam dos alunos maior grau de reflexão sobre aspectos estruturais do gênero e da própria língua e de aspectos sociodiscursivos associados aos contextos diversificados de interação (SCHNEUWLY, 2004).

Fazemos a ressalva, aqui, de que, embora concordemos que o oral formal (a oralidade letrada) deva ser o foco das práticas orais na escola, não descartamos a riqueza de se trabalhar com gêneros diversificados, mesmo que sejam informais, contanto que permitam possibilidades de reflexões de várias ordens como as linguísticas, as das estratégias discursivas, dos aspectos prototípicos da fala, da compreensão oral, etc. 
Sobre quais os gêneros orais estão presentes na sala de aula, os formadores apontaram a falta de clareza dos professores quanto ao fato de citarem gêneros escritos. $\mathrm{Na}$ linha que converge para a oralidade na escola como discussão mais ampla do que apenas a leitura em voz alta, está a fala de F6: "[p]arece que a oralidade é ler em voz alta. Oralizar um texto escrito. Os professores da educação básica têm um pouco essa concepção de que trabalhar oralidade é você mandar o menino ler em voz alta" (F6).

F7 também afirma que a oralidade é entendida por muitos professores da ficha como realização apenas de leitura em voz alta de gêneros escritos. Segundo o formador, ao fazer alusão a fragmento lido: "não é só leitura de jornal. Pode ser, mas tem que trabalhar as nuances da oralidade". Dos gêneros citados, destaca a história em quadrinhos. Para ele, "a história em quadrinhos é muito bom pra trabalhar oralidade, variação linguística, trabalhar a representação do oral ali no escrito" (F7).

Embora o professor da ficha que mencionou HQ tenha feito isso citando como demais gêneros 'Leitura de jornais' e 'revistas informativas' - suportes para gêneros escritos - e 'textos literários' (sem fazer menção aos de tradição oral), F7 vislumbra, a partir de um olhar voltado para o eixo da oralidade, a possibilidade de explorar conteúdos variados através do gênero textual que tanto agrada aos alunos (MENDONÇA, 2002).

Importante ressaltar que não defendemos apenas o trabalho com gêneros que agradem aos alunos. O que se está em questão, aqui, é a necessidade da seleção de gêneros significativos no sentido de fazerem parte, de algum modo, da vida dos alunos. Dessa forma, é mais provável que eles entendam a relevância do que estão refletindo. Maurer (2011), ao refletir sobre o papel da escola quanto aos gêneros textuais orais, afirma que cabe a esta instituição dotar os alunos de ferramentas necessárias para interagirem de forma plena na sociedade: “il s'agit de préparer les futurs adultes à maîtriser des compétences de communication requises dans la vie quotidienne ou dans la vie professionnelle" (MAURER, 2001, p. 35) ${ }^{5}$.

Sobre essa questão, ou seja, quais gêneros contemplar, F10 afirma:

Eu acho que tem os gêneros que eles devem vivenciar. Mas veja qual é a minha dúvida, o ano passado foi ano de copa, aí uma das professoras de português da Escola A., que foi minha aluna daqui, orientanda de mestrado já, entrou esse ano, E. P., não sei se você sabe quem é, muito boa. Então ela teve a ideia porque ela sabe que precisa desenvolver a oralidade, ela fez um projeto conjunto com a escola, que era assim a copa nos bancos dos réus, porque tinha gente que era a favor, gente contra, porque fazer aqui, não fazer aqui, porque ficou pronta, porque não ficou, a comercialização, tem gente que não gosta de futebol e acha que a gente é obrigado a viver dias de futebol. Ela fez um júri simulado dentro da quadra da escola com todo fundamental 2, e tinha menino que só foi pra ser plateia porque teve uma designação de papeis lá, e teve uma chamada no rádio, uma notícia sobre essa coisa da cidadania que foi julgar a copa, saber se valia a pena realmente ter a copa no país, se o legado fica mesmo e tal, e eu achei genial a iniciativa, o conteúdo, a forma de realização, foi no contraturno, com todo mundo da escola assistindo, podia ir convidado, que era um debate interessante, que interessava a todo mundo (F10).

No exemplo citado por F10, identificamos uma atividade que envolveu um júri simulado, mas também notícia, conforme apontado, além de, provavelmente, outros gêneros

\footnotetext{
5 "Isto é, preparar os futuros adultos a desenvolver competências de comunicação exigidas na vida cotidiana ou na vida profissional” (MAURER, 2001, p. 35, tradução nossa).
} 
como o convite destinado aos pais. Nesse excerto, temos a ilustração de uma experiência de um projeto que envolvia toda a escola, com temática contemporânea à época e que, portanto, atraiu a comunidade escolar independente dos papeis, diretos ou indiretos, vividos pelos participantes do evento. Esse relato de experiência didática ilustra bem o ensino que se relaciona às práticas sociais de um modo geral. Segundo Bazerman (2011), a seleção de gêneros distintos, configurando um sistema de gêneros, é necessária para dar conta de uma rede complexa do modo de vida organizado (BAZERMAN, 2011).

Já F9 chama atenção para a forma como a teoria dos gêneros tem sido compreendida pelos professores. Segundo o formador, os gêneros textuais têm sido temática muito presente na vida do professor (formação inicial, encontros para formação continuada, revistas para professores, livros didáticos, etc.); no entanto, muitas vezes eles não conseguem entender o que se discute teoricamente: "É uma teoria de gêneros que entra assim 'vrup' na cabeça do professor e tá circulando no livro didático, não a teoria, mas os gêneros. Tinha um livro que ele tava fazendo com o gênero o que foi feito com a gramática muito tempo" (F9).

A reflexão de F9, embora não esteja voltada para especificidade dos gêneros orais, traz à tona uma questão que ainda pode ser problemática para alguns professores: a própria noção de gêneros textuais. Considerando isso, seria fácil compreender porque alguns professores citaram suportes ao invés de gêneros.

Em relação aos relatos de atividades, F9 acredita, de acordo com suas palavras, que "o professor tá tentando entender o que fazer em sala de aula" (F9), o que seria importante para a oralidade se fazer presente, de algum modo, na aula de português. E essa entrada da oralidade aconteceria de modo integrado aos eixos com os quais o professor está mais acostumado a trabalhar: a leitura e a escrita. É por isso que F9 observa a associação com a leitura no primeiro relato e com a escrita no segundo: "Há aqui um entrecruzamento entre oralidade e o ensino da leitura, da interpretação de texto [sobre o primeiro]. Esse também está bem próximo do primeiro, mas aí ele vai puxando pra escrita [sobre o segundo]" (F9).

F9 também ressalta a importância da presença da oralidade através das duas primeiras atividades relatadas. Mas essa relevância é entendida pelo formador como possibilidade de construção de conhecimento em geral e não especificamente de conhecimentos sobre a modalidade oral da língua. E a razão para isso está no fato da oralidade não estar posta como objeto de ensino:

Aqui é aquela ideia, né? Você não coloca a oralidade como objeto de ensino nem objeto de aprendizagem, mas ela usa a oralidade. O que é importante porque como é que você vai construir conhecimento com os alunos em silêncio em sala de aula? (F9).

Reforçando seu argumento, F9 exemplifica que o debate da segunda atividade não visa contemplar questões como o gênero oral, o texto falado argumentativo ou aspectos prototípicos da fala, e sim preparar o aluno para ter o que dizer na atividade de produção textual. De acordo com o formador, o que acontece na atividade em questão e normalmente nas salas de aula é: "Falar pra escrever. Oralidade parece que nunca é trabalhada em si mesma" (F8).

Também a partir da reflexão sobre o gênero debate na escola, F10, ao se lembrar de uma dissertação que orientou, questiona até que ponto a sistematização valeria a pena:

Na dissertação de D., numa certa hora ela veio me trazer, porque ela estudou análise linguística, mas ela foi mostrar, inclusive, que teve menos análise linguística da oralidade do que teve da escrita. Aí eu digo, oh, D., e depois de tanta coisa que se fala na escola é que se faz vai fazer análise linguística? Sistematizar, registrar conhecimento das regras, estratégias, é pra fazer isso? 
Você perde o debate de vista, perde o conteúdo da fala. Eu fiquei meio intrigada com ela. E é pra fazer mesmo ou não é? (F10).

Para nós, não se trata de uma equidade quantitativa de reflexões sistemáticas entre a modalidade oral e escrita. Não se trata também de didatizar todas as falas que acontecem na aula de Português. Entretanto, algumas delas precisam ser tratadas como objeto de ensino de modo que as estratégias e as regras sejam pensadas e repensadas em prol do conteúdo da fala, da interação em si, com seus propósitos e formas para atingi-los. Maurer (2001), ao mencionar uma didática baseada no estudo dos gêneros orais, indica "la nécessité d'une réflexion spécifique sur l'oral, posé comme un objet d'apprentissage comme les autres, d'égale importance" (MAURER, 2001, p. 58) ${ }^{6}$.

A partir do relato de atividade da ficha em que o professor contempla o gênero entrevista, F8 destaca que a proposta é desafiadora, sobretudo porque acredita que a entrevista tenha sido muito utilizada na escola, mas poucos se preocupam com questões como marcas da oralidade. $\mathrm{O}$ formador já tentou fazer um trabalho dessa natureza quando estava na educação básica, conforme destaca:

Era um trabalho com memórias, os alunos iriam usar os celulares para gravar as entrevistas com pessoas mais velhas, a ideia era transcrever, ver as marcas de oralidade, mas isso com menino de $6^{\text {a }}$ série é um inferno, né? Isso é uma coisa que dispende uma energia enorme do professor porque é um trabalho ao qual a gente não está acostumado, é um trabalho que realmente dá muuuuito trabalho. É um trabalho árduo pra dizer o mínimo (F8).

F8 mencionou aspectos importantes do ensino do oral na escola: a falta de costume do professor em realizar atividades e a consequente dificuldade para conduzi-las, o que concordamos com base em outros estudos citados como, por exemplo, o de Rodrigues e Luna (2016). Quanto ao fato de F8 achar árduo, ressaltamos que, na mesma ótica, seria árduo o trabalho com a produção escrita (com reescrita), com a leitura de clássicos, com projetos, trabalhos interdisciplinares, trabalhos de campo, etc., etc.

Já F10 enfatiza em seu comentário sobre a atividade da entrevista na reflexão proposta pelo professor sobre marcas da oralidade: "Eu acho que você falar de marcas de oralidade na escrita sem o aluno transcrever, eu acho que chega pra eles de modo muito acessório" (F10). Apesar da relevância da proposta, F10 critica a metodologia. Em sua opinião, o processo de transcrição seria fundamental para que os alunos entendessem melhor a relação fala-escrita. De certo modo, corroboramos o formador no sentido de que a atividade poderia ser mais detalhada e repensada. Contudo, não poderemos retirar o mérito da única das três propostas que, de fato, considera o oral como objeto autônomo de ensino, mesmo passível de ajustes.

A dificuldade apresentada por professores é, dentre outras razões, reflexo da formação inicial e continuada desses docentes (RODRIGUES; LUNA, 2016). Isso se confirma também com a fala do formador ao mencionar sua formação. F6, por exemplo, formado já na década de 2000, ressalta que sentiu falta de um debate sólido sobre ensino da oralidade, o que gerou dificuldades quando iniciou sua vida profissional ministrando aulas na Educação Básica:

Até a nossa graduação a gente não tinha uma discussão profunda sobre oralidade, eu tô falando assim no aspecto do ensino da oralidade como

\footnotetext{
6 "A necessidade de uma reflexão específica sobre o oral, colocado como um objeto de aprendizagem como os outros, de igual importância” (MAURER, 2001, p. 58, tradução nossa).
} 
objeto de ensino, a gente não tinha isso, e quando a gente chega inclusive pra ser professor da educação básica a gente tem muita dificuldade (F6).

Segundo F6, essa dificuldade se estendeu em outra etapa de sua trajetória profissional, ou seja, quando virou professor universitário, responsável pela formação dos futuros professores de português. Nas palavras do formador, temos: "quando a gente vai ensinar no ensino superior a gente também tem essa dificuldade, então a gente vai pesquisando, procurando coisas daqui e dali pra trazer esse objeto com um mínimo de profissionalidade" (F6). O que F6 considera como positivo no contexto atual é que, apesar de não existirem muitas pesquisas sobre a questão, elas existem, sobretudo se comparado à época em que fez o curso de licenciatura: "hoje essas pesquisas têm tido mais força, mas imagine isso na época da nossa graduação, a gente tinha dois livros pra discutir oralidade" (F6).

A fala de F6 mostra um formador consciente de suas carências e, ao mesmo tempo, autônomo no processo de superá-las. Freire, em Pedagogia da Autonomia, ressalta a importância dessa postura: "[c]omo professor não me é possível ajudar o educando a superar sua ignorância se não supero permanentemente a minha". (FREIRE, 2010, p. 95). Para formar um aluno autônomo, portanto, é necessário ser autônomo enquanto professor.

Apesar do ensino da oralidade ser refletido em algumas pesquisas e em documentos oficiais que regem a prática docente, conforme apontado em tópico anterior, ainda é necessário que o formador desperte essa relevância para o futuro professor. Isso é o que propõe F7:

Quando os meninos vão observar e quando eles estão na regência eles são orientados a observar como a oralidade é tratada em sala de aula e eles são instruídos a ensinar também o eixo da oralidade nas regências. Então, a gente tenta dar a mesma atenção à oralidade, como dá pra produção de textos, pra análise linguística, e como dá pra literatura (F7).

Na perspectiva de F7, a oralidade é um eixo tão importante quanto os outros e é por isso que o formador orienta, nos componentes de estágio, a observação do trato dado à oralidade na escola e ao ensino no momento em que o licenciando atua como professor (ministrando aula, conduzindo oficinas, etc.).

\section{Considerações finais}

Como se pode observar através da análise dos dados, o eixo de ensino da oralidade, ou seja, o trabalho de compreensão, produção e análise linguística de textos orais, suscita muitas reflexões por parte dos professores universitários entrevistados que atuam na formação inicial de futuros professores, dos estudantes de uma licenciatura em Letras-Português.

A fala dos formadores evidencia que suas concepções sobre didática da oralidade segue, em sua maioria, na mesma direção de estudos recentes, conforme apontado na reflexão teórica deste artigo. Esse fato não impede que estes professores tenham suas inquietações e façam seus próprios questionamentos sobre o ensino-aprendizagem da oralidade, contribuindo, assim, para a continuidade do debate sobre a temática em suas aulas, em pesquisas e, principalmente, nas escolas.

A clareza da compreensão sobre a importância de trabalhar com textos orais na escola (o porquê), os conteúdos e as competências a serem desenvolvidas (o quê) e as estratégias metodológicas (o como) é essencial para que a reflexão sistemática da oralidade 
seja possível. Por fim, destacamos que a Licenciatura em Português é um espaço profícuo para que a construção destes saberes docentes seja iniciada.

\section{Referências}

ARAÚJO, D. L. de; RAFAEL, E. L.; AMORIM, K. V. Estudos Linguísticos e oralidade: uma visão do objeto de estudo e de ensino em cursos de Letras da Paraíba. In: ARAÚJO, D. L. de; SILVA, W. M. da. (Org.). Oralidade em foco: conceitos, descrição e experiências de ensino. Campina Grande: Bagagem, 2013, p. 55-76.

ÁVILA, E.; NASCIMENTO, G.; GOIS, S. Ensinando a oralidade: revisitando documentos oficiais e conversando com professores. In: LEAL, T. F.; GOIS, S. (Org.). A oralidade na escola: a investigação do trabalho docente como foco de reflexão. Belo Horizonte: Autêntica Editora, 2012.

BAZERMAN, C. Gêneros Textuais, tipificação e interação. São Paulo: Cortez, 2011.

BOTLER, L. M. A. R. Gêneros orais e ensino de língua portuguesa: concepções e práticas. Recife, 2013. 210f. Dissertação (Mestrado em Educação), Universidade Federal de Pernambuco.

BRASIL. Parâmetros curriculares nacionais: terceiro e quarto ciclos do ensino fundamental: língua portuguesa. Brasília: MEC/Secretaria de Educação Básica, 1998.

. Guia de livros didáticos: PNLD 2015: língua portuguesa: ensino médio. Brasília: Ministério da Educação, Secretaria de Educação Básica, 2014.

COSTA-MACIEL, D. A. G. da. Oralidade e ensino: saberes necessários à prática docente. Recife: Ed. Universidade de Pernambuco, 2013.

FREIRE, P. Pedagogia da autonomia: saberes necessários à prática educativa. São Paulo: Paz e Terra, [1996] 2010.

MAGALHÃES, T. G. Concepções de oralidade: a teoria nos PCN e PNLD e a prática nos livros didáticos. Rio de Janeiro, 2007. 211f. Tese (Doutorado em Letras). Programa de PósGraduação em Letras, Universidade Federal Fluminense.

MAURER, B. Une didactique de l'oral : du primaire au lycée. Paris: Bertrand-Lacoste, 2001.

MENDONÇA, M. Um gênero quadro a quadro: a história em quadrinhos. In: DIONÍSIO, A.; MACHADO, A. R.; BEZERRA, M. A. (Org.). Gêneros textuais e ensino. Rio de Janeiro: Lucerna, 2002, p. 194-207.

PERNAMBUCO. Parâmetros para a Educação Básica do Estado de Pernambuco Parâmetros Curriculares de Língua Portuguesa para o Ensino Fundamental e Médio. Recife: SEDUC-PE, 2012.

RODRIGUES, S. G. C.; LUNA, E. A. dos A. O ensino da oralidade no contexto do Ensino Fundamental. In: RODRIGUES, S. G. C.; LUNA, E. A. dos A.; COSTA-MACIEL, D. A. G. 
da. (Org.). Oralidade \& Leitura: olhares plurais sobre Linguagem e Educação. Recife: Editora UFPE, 2016.

SCHNEUWLY, B. Palavra e ficcionalização: um caminho para o ensino da linguagem oral. In: SCHNEUWLY, B.; DOLZ, J. et al. Gêneros orais e escritos na escola. São Paulo: Mercado das Letras, 2004, p. 109-124.

Recebido em: junho de 2017.

Aprovado em: agosto de 2017. 